\title{
Long-term Exposure to Retrovirally Expressed Granulocyte-Colony-stimulating Factor Induces a Nonneoplastic Granulocytic and Progenitor Cell Hyperplasia without Tissue Damage in Mice
}

\author{
Juliana M. Chang, " Donald Metcalf," Thomas J. Gonda, ${ }^{\ddagger}$ and Gregory R. Johnson* \\ ${ }^{*}$ Cancer Research Unit, The Walter and Eliza Hall Institute of Medical Research and ${ }^{\ddagger}$ Ludwig Institute for Cancer Research, \\ Melbourne Tumor Biology Branch, Royal Melbourne Hospital 3050, Melbourne, Australia
}

\begin{abstract}
Murine marrow cells infected with a retroviral vector (MPZen) bearing a granulocyte-colony-stimulating factor (G-CSF) cDNA insert were transplanted into lethally irradiated recipients to study the effects of autocrine production of G-CSF in normal hemopoietic cells. Most animals remained healthy with no evidence of tissue damage throughout the observation period (4-30 wk) despite high circulating G-CSF levels (range 2,000-26,000,000 U/ml). A dramatic neutrophilic granulocytosis was observed in all hemopoietic tissues with neutrophilic infiltration occurring in the lung and liver. Spleen, peritoneal, and peripheral blood cellularity increased approximately three-, two-, and eightfold, respectively, but total bone marrow cell counts remained unchanged. Progenitor cell numbers granulocyte-macrophage colony-forming cell (GM-CFC), granulocyte colony-forming cell (G-CFC), burst-forming uniterythroid (BFU-E), colony-forming unit-erythroid (CFU-E) and mixed colony-forming cells (Mix-CFC) were elevated between 10-100-fold in the spleen, peritoneal cavity, and peripheral blood, but were unaffected or slightly depressed in the marrow.

No tumors developed in syngeneic recipients transplanted with bone marrow or spleen cells from such mice, confirming the nonneoplastic nature of the hyperplasia induced by chronic G-CSF stimulation. These experiments also indicated the stable integration of MPZen vectors in infected cells, as evident from the continuous expression of the inserted gene for at least $6 \mathrm{mo}$, and from the ability of infected stem cells from the primary recipients to express the gene in lethally irradiated secondary recipients.
\end{abstract}

\section{Introduction}

Granulocyte colony-stimulating factor (G-CSF), ${ }^{1}$ was originally detected because it induced differentiation in a murine

Address reprint requests to Dr. Chang, The Walter and Eliza Hall Institute of Medical Research, P.O. Royal Melbourne Hospital, 3050 Melbourne, Australia.

Received for publication 17 April 1989 and in revised form 18 July 1989.

1. Abbreviations used in this paper: AML, acute myeloblastic leukemia; BFU-E, burst-forming unit-erythroid; CFU-E, erythroid CFU; CFU-S, spleen CFU; Epo, erythropoietin; 5-FU, 5-fluorouracil; G-CSF, granulocyte-colony-stimulating factor; GM-CFC, granulocyte-macrophage colony-forming cell; Meg-CFC, megakaryocyte colony-forming cells; Mix-CFC, mixed colony-forming cell; SCM, spleen cell conditioned medium.

J. Clin. Invest.

(c) The American Society for Clinical Investigation, Inc.

$0021-9738 / 89 / 11 / 1488 / 09 \$ 2.00$

Volume 84, November 1989, 1488-1496 myelomonocytic leukemic cell line, and it stimulated granulocyte colony formation by normal progenitor cells (1). The hemopoietic actions of this regulator are restricted exclusively to cells of the neutrophilic granulocyte lineage (2-4). Murine and human G-CSF have been purified from various sources (1-3) and complementary DNAs encoding G-CSF have been cloned (5-7). The broad species cross-reactivity of human G-CSF has allowed the in vivo action of purified recombinant human G-CSF (rhG-CSF) to be studied in mice $(8,9)$, hamsters $(10)$, monkeys $(11)$, and man $(12,13)$. The predominant response in all species was a rapid dose-dependent neutrophilia (5-10-fold in peripheral blood of all species). In mice, chronic G-CSF treatment elicited not only increased granulopoiesis in the spleen but also increased erythropoiesis, megakaryocytopoiesis, and elevated numbers of multipotential stem cells (CFU-S) and progenitors of all hemopoietic lineages; these changes were associated with a 50\% increase in spleen cellularity $(8,9)$. Similar but less dramatic changes were noted in the bone marrow, while little change in peripheral blood cell types other than neutrophils was observed $(8,9)$. All spleen and blood parameters returned to control values after cessation of G-CSF treatment.

Although there have been many reports supporting the hypothesis that autocrine stimulation is a mechanism of transformation (14-16), previous studies in this and other laboratories have documented that dysregulated autocrine production of GM-CSF $(17)$ or multi-CSF (IL-3) $(18,19)$ in normal cells leads to a fatal but nonneoplastic myeloproliferative disorder in vivo. The role of autostimulation of hemopoietic cells in the development of human leukemias is also questionable. Of 22 acute myeloblastic leukemia (AML) patients' cells tested for G-CSF gene rearrangements, only two contained rearranged G-CSF genes and neither secreted detectable G-CSF (20). In view of the potential use of G-CSF in the treatment of a number of human hematological disorders and the possible contribution of hemopoietic cell overstimulation in leukemic transformation, we have developed an animal model system in which high circulating levels of G-CSF can be maintained for periods of at least $6 \mathrm{mo}$. We report here our observations on the hemopoietic changes induced in these mice.

\section{Methods}

Construction and selection of G-CSF retrovirus. The 0.77-kb Eco RIDra I fragment of G-CSF cDNA was removed from pMG2 (kindly provided by Dr. S. Nagata (5), Osaka Bioscience Institute, Osaka, Japan) and ligated into the Eco RI-Eco RV site of pIC-19H (21). The G-CSF cDNA fragment was then excised as a Sal I-Xho I fragment and ligated into the Xho I site of pMPZen (Fig: 1).

Helper-free MPZen(G-CSF) virus-producing fibroblast lines were made by co-transfecting $\psi 2$ cells (22) with pSV2Neo (23) and 


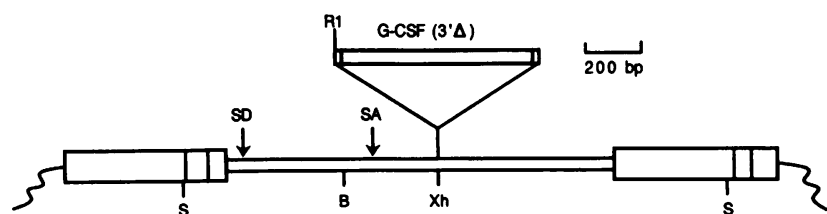

Figure 1. Schematic representation of MPZen(G-CSF) retrovirus. The derivation of the G-CSF $\operatorname{cDNA}\left(3^{\prime} \Delta\right)$ is described in Methods, and the vector pMPZen has been described previously (17). Arrows labeled SD and SA indicate splice donor and acceptor sites used to generate the subgenomic RNA encoding the gene 3 ' to SA. Restriction endonuclease sites are abbreviated as follows: B, Bam HI, S, Sac I, RI Eco RI, Xh, Xho I.

pMPZen(G-CSF), as described previously (17). They were screened by infecting FDC-P1 cells (24) (a cell line totally dependent on GM-CSF or multi-CSF for survival) to determine the frequency and levels of G-CSF production by infected clones. Briefly, $1 \times 10^{5} \mathrm{FD}$ cells were cocultivated with irradiated (3.0-3.5 Gy) MPZen(G-CSF) producers in 10\% PWM-SCM (pokeweed mitogen-stimulated spleen cell conditioned media, [25]), then harvested, washed and plated in agar-medium at low density $(50-1,000$ cells $/ \mathrm{ml})$ in the presence of PWM-SCM. After $7 \mathrm{~d}$ incubation, 20 individual colonies were picked from each group, placed in Dulbecco's modified Eagle's medium (DME) in $20 \%$ FCS for $3 \mathrm{~d}$ and their supernatants were tested for G-CSF activity.

Genomic DNA analysis. High molecular weight DNA was isolated from cell lines and various mouse tissues by guanidine $\mathrm{HCl}$ extraction (26) and digested with Sac I or Eco RI. Digested DNA was analyzed by Southern blotting (27) and probed with an $\alpha-{ }^{32} \mathrm{P}$-labeled G-CSF cDNA fragment, using conditions described previously (18).

Infection of normal hemopoietic cells and hemopoietic growth factor assays. Day 4 post-5-fluorouracil-treated (5-FU) bone marrow cells (2 $\times 10^{6}$ ) were infected with MPZen(G-CSF) or MPZipNeo (28) using conditions as previously described (17). Multi-CSF and GM-CSF were detected by $32 \mathrm{D} \mathrm{cl.3}$ and FDC-P1 microwell assays, respectively (29), while G-CSF was assayed by its ability to induce differentiation in colonies of the murine myelomonocytic cell line WEHI-3B $\mathrm{D}^{+}(1)$. Erythropoietin (Epo) was assayed on day 12-13 CBA/CaH/WEHI fetal liver cells as described previously (30).

Mice. Mice used were 2-3-mo old C57BL/6J/WEHI obtained from stocks raised under SPF conditions at The Walter and Eliza Hall Institute of Medical Research. For transplantation studies, animals were irradiated $(9.0-9.5 \mathrm{~Gy}, \gamma$-rays generated by cobalt- 60 at $0.39 \mathrm{~Gy} / \mathrm{min}$ at $1.5 \mathrm{~m}$ ) and injected intravenously with the required number of cells within $3 \mathrm{~h}$ of irradiation. Mice were monitored weekly and examined at various times. Peripheral blood collected from the axillary plexus of anesthetized animals was used to determine serum G-CSF levels, nucleated and differential cell counts, and hematocrit. After killing the mice by exsanguination, peritoneal cells were harvested by injecting 2 $\mathrm{ml}$ of medium into the peritoneal cavity and collecting the fluid; bone marrow cells removed by flushing both femurs and spleen removed and weighed. Viable (by eosin exclusion) and total nucleated cell counts were determined for each cell suspension. All organs were fixed in $10 \%$ formalin saline, sectioned, and replicate sections stained with hematoxylin and eosin, Alcian blue-safronin, or Luxol-Fast Blue.

Production of conditioned media. Conditioned media from bone marrow, spleen, or peritoneal cells were prepared using dispersed cell suspensions of $10^{5}$ or $10^{6} \mathrm{cells} / \mathrm{ml}$ in 2 -ml cultures containing $20 \%$ FCS in DME $\pm 10 \%$ PWM-SCM and incubated for $7 \mathrm{~d}$ at $37^{\circ} \mathrm{C}$.

$C F U-S, B F U-E, C F U-E$, and $C F C$ assays. Lethally irradiated C57BL/6J mice were injected intravenously with $0.25-1 \times 10^{5}$ syngeneic day 4 post-5-FU-treated bone marrow cells infected with MPZen(G-CSF) or MPZipNeo (28). 13 d later, individual spleen colonies were removed from nonconfluent spleens and single cell suspensions prepared as previously described (31).
CFC numbers were determined by culturing $10 \%$ of the cells from each spleen colony, bone marrow $\left(5 \times 10^{4} / \mathrm{ml}\right)$, spleen $\left(1 \times 10^{5} / \mathrm{ml}\right)$ or peritoneal cells $\left(1 \times 10^{5} / \mathrm{ml}\right)$ in triplicate $1 \mathrm{ml}$ agar cultures. Light density peripheral blood mononuclear cells $\left(0.1-1 \times 10^{5} / \mathrm{ml}\right)$ were cultured after isolation by Ficoll-Hypaque centrifugation $(d 1.077$ $\mathrm{g} / \mathrm{cm}^{3}$; Pharmacia Fine Chemicals, Piscataway, NJ). When required, cultures were maximally stimulated by the addition of PWM-SCM or rhG-CSF (kindly provided by Dr. Larry Souza, AmGen Biologicals, Thousand Oaks, CA) for the detection of GM-CFC and G-CFC, respectively. Colonies ( $>50$ cells) were scored at day 7 . Total CFC numbers were calculated after adjustments for marrow and spleen cellularity (one femur representing 6\% of total marrow [32]).

Colonies derived from CFU-E were scored after $2 \mathrm{~d}$ while those derived from BFU-E and mix-CFC (33) were counted at day 7 in $1 \mathrm{ml}$ methylcellulose cultures containing 2.0 U Epo (30) and maximal concentrations of PWM-SCM (25).

Where required, agar cultures were fixed with $2.5 \%$ glutaraldehyde, transferred to glass slides, and stained for cholinesterase to specifically stain megakaryocytes and/or stained with Luxol-Fast-Blue and hematoxylin for differential granulocyte and macrophage colony counts.

Transplantation studies. Bone marrow or spleen cells $\left(10^{6}\right)$ from four primary animals (transplanted with $10^{6} \mathrm{MPZen}$ (G-CSF)-infected marrow cells $2-4$ wk previously) were injected intravenously, intraperitoneally, or subcutaneously into normal $(n=72)$ or sublethally irradiated (4.5 Gy, $n=72$ ) secondary syngeneic recipients. In addition, 19 lethally irradiated $(9.0 \mathrm{~Gy})$ mice were injected intravenously with $10^{6}$ marrow cells from seven primary animals.

\section{Results}

Screening MPZen(G-CSF) virus producers. G-CSF activity (range 800-20,000 U/ml) was detectable in the supernatants of 10 out of $20 \mathrm{G} 418$-resistant transfected $\psi 2$ clones. $50 \%$ of these G-CSF-producing clones were able to infect FDC-P1 cells, which when clonally expanded, secreted G-CSF. The $\psi 2$ clone with the highest titer (G12) infected 35\%, i.e., 7 of 20 colonies of cultured FDC-P1 cells, and supernatants of the infected FDC-P1 clones contained between 13,000 and $18,400 \mathrm{U} / \mathrm{ml}$ G-CSF activity.

Infection of CFU-S and G-CSF expression in spleen colony cells. Using the CFU-S infection protocol as described previously (17), MPZen(G-CSF) infected post-5-FU-treated marrow cells were transplanted into lethally irradiated syngeneic mice. High molecular weight DNA was extracted from individual spleen colonies dissected $13 \mathrm{~d}$ after transplantation, and digested with Sac I, which cuts once within each LTR of MPZen(G-CSF). Of the 33 spleen colonies analyzed by Southern blotting with an $\alpha-{ }^{32} \mathrm{P}$-labeled G-CSF probe, 11 contained viral G-CSF sequences at an average level of one copy per cell (Table I). Of the viral DNA-positive spleen colonies, $50 \%$ produced autonomous colonies in soft agar at a frequency of $\sim 5 \%$ of those stimulated by PWM-SCM, and 8 of 11 produced G-CSF (range 1,000-10,000 U/ml) in the conditioned media. In contrast, cells from spleen colonies from control mice or colonies that were viral DNA-negative never formed colonies in soft agar in the absence of added stimulus. However, low levels of G-CSF (range 300-800 U/ml) were detected in the conditioned media from 3 of 13 viral DNA-negative spleen colonies; this may have been produced by single infected cells overgrown by spleen colony cells, or from the migration of small numbers of virally infected colony cells to adjacent spleen colonies.

The multipotential cell origin of the spleen colonies was evident from the presence of erythroblasts, eosinophils, mono- 
Table I. Analysis of Spleen Colonies*

\begin{tabular}{|c|c|c|c|c|}
\hline \multirow{2}{*}{$\begin{array}{l}\text { Spleen } \\
\text { colony } \\
\text { number }\end{array}$} & \multirow{2}{*}{$\begin{array}{l}\text { Viral } \\
\text { DNA }^{3}\end{array}$} & \multicolumn{2}{|c|}{ Total CFC } & \multirow[b]{2}{*}{ G-CSF activity" } \\
\hline & & $-\mathrm{SCM}$ & $+\mathrm{SCM}$ & \\
\hline & & & & $U / m l$ \\
\hline 1 & - & 0 & 0 & 0 \\
\hline 2 & + & 0 & 105 & 0 \\
\hline 3 & + & 10 & 225 & 1,000 \\
\hline 4 & - & 0 & 35 & 0 \\
\hline 5 & + & 10 & 180 & 5,000 \\
\hline 6 & + & 0 & 365 & 2,000 \\
\hline 7 & + & 0 & 410 & 1,250 \\
\hline 8 & - & 0 & 185 & 720 \\
\hline 9 & + & 15 & 395 & 7,000 \\
\hline 10 & - & 0 & 155 & 0 \\
\hline
\end{tabular}

* Individual spleen colonies were dissected $13 \mathrm{~d}$ after transplantation of irradiated mice with $0.25-1 \times 10^{5}$ post-5-FU-treated bone marrow cells cocultured with MPZen(G-CSF) virus-producing $\psi 2$ fibroblasts. $\ddagger 1 / 6,4 / 7$, and $4 / 5$ spleen colonies were dissected from three spleens. $\S$ Viral DNA was detected by Southern blot analysis of Sac I digests using a G-CSF cDNA probe.

" 7-d conditioned media $(2 \mathrm{ml})$ initiated with $10 \%$ of cells from each spleen colony (each spleen colony having between 1 to $20 \times 10^{6}$ cells).

cytes, macrophages, and blast cells in cytospin preparations of both viral DNA-positive and negative spleen colonies. There was no obvious difference in the cellular composition of these two types of spleen colony.

$G-C S F$ expression in reconstituted mice. The results described above provide evidence for the insertion of virally encoded G-CSF into multipotential cells (CFU-S) and expression in their progeny. The effect of overexpressing G-CSF in vivo was then studied by examining groups of lethally irradiated mice transplanted with $1 \times 10^{6} \mathrm{MPZen}(\mathrm{G}-\mathrm{CSF}$ )-infected post-5-FU bone marrow cells (G-CSF mice). Groups of three to nine mice were killed at various times after transplantation and their hemopoietic parameters were examined (Tables II-V). In a survey of 21 animals over an observation period of 6-7 mo, only one became ill with weight loss, tremors, labored breathing, and had a hunched appearance. This mouse had no detectable tumors or spleen enlargement, a white cell count of $0.8 \times 10^{6} / \mathrm{ml}$ and a high hematocrit $(64 \%)$, while marrow cel- lularity was half that of normal mice. All the other animals appeared healthy.

Southern blot analysis was carried out on Sac I digests of DNA from various mouse tissues (Fig. 2). The intensity of bands corresponding to the provirus $(2.9 \mathrm{~kb})$ compared with those corresponding to the endogenous G-CSF gene ( $7 \mathrm{~kb}$ ) indicated that the mean number of proviral copies per cell varied between 1 and 5 . The presence of multiple integrants in both the bone marrow and spleen of two mice (Fig. 2) was confirmed by Eco RI digestion (which cuts once in the provirus) and suggests that in these two mice both tissues had been repopulated by a single clone.

G-CSF levels in reconstituted mice. Serum G-CSF levels in the G-CSF mice were consistently elevated (mean $1.7 \times 10^{6}$ $\mathrm{U} / \mathrm{ml}$, range $2,000-26,000,000 \mathrm{U} / \mathrm{ml}, n=25$ ) at all timepoints examined (between 2 and $30 \mathrm{wk}$ ) after transplantation. In contrast, low G-CSF activity (mean $300 \mathrm{U} / \mathrm{ml}$ ) was detectable in the sera of only 2 of 17 control mice examined (Table II). Conditioned media prepared by incubating hemopoietic tissues without added growth factors contained variable levels of G-CSF activity. To maintain cells and optimize production of G-CSF, the tissues were incubated in 10\% PWM-SCM which resulted in a mean fivefold increase in G-CSF activity. Under these conditions, the calculated total tissue production of G-CSF was highest in the peritoneal cavity followed by the spleen and bone marrow, with little activity detectable in media conditioned by tissues from control animals (Table II).

Hematological parameters. Compared with control MPZipNeo-infected animals, all G-CSF mice exhibited an increase in cellularity in the spleen (2-4-fold), peritoneal cavity (2-fold), and peripheral blood (5-13-fold) with no change in bone marrow cellularity (Table III).

Differential cell counts performed on stained smears of cells from the G-CSF reconstituted animals (Fig. 3) revealed an abnormal frequency of various subpopulations. This was evident by $4 \mathrm{wk}$ after transplantation but tended to return to a normal pattern by 6 mo. Most striking was the marked neutrophilia seen in all tissues. At 4,12 , and $30 \mathrm{wk}$ after transplantation, 8.5, 4.0, and 2.6-fold increases, respectively, in neutrophils were observed in the sum of total marrow, spleen, peritoneum and peripheral blood $(1 \mathrm{ml})$ of the G-CSF mice compared to control animals. Similarly, monocyte and macrophage levels in the G-CSF mice were elevated fivefold at $4 \mathrm{wk}$ after reconstitution and declined to normal levels by $6 \mathrm{mo}$, while the number of erythroblasts decreased from 2.5 to 1.4-

Table II. G-CSF Levels in Sera and Conditioned Media from Transplanted Mice

\begin{tabular}{|c|c|c|c|c|c|c|}
\hline \multirow[b]{2}{*}{ Virus } & \multirow{2}{*}{$\begin{array}{l}\text { Number } \\
\text { of mice }\end{array}$} & \multirow{2}{*}{$\begin{array}{c}\text { Weeks after } \\
\text { transplantation }\end{array}$} & \multicolumn{4}{|c|}{ G-CSF concentrations $\left(\times 10^{-3} \mathrm{U} / \mathrm{ml}\right)$} \\
\hline & & & Serum & Bone marrow* & Spleen ${ }^{*}$ & Peritoneum* \\
\hline \multirow[t]{3}{*}{ MPZen(G-CSF) } & 9 & $2-4$ & $101 \pm 108$ & $1.4 \pm 0.7^{\ddagger}$ & $2.7 \pm 1.1^{\ddagger}$ & $7.4 \pm 3.2^{\ddagger}$ \\
\hline & 9 & $5-14$ & $7,030 \pm 10,290$ & $2.2 \pm 4.5^{\S}$ & $2.0 \pm 4.3^{\S}$ & $9.3 \pm 15.8^{\S}$ \\
\hline & 7 & $26-30$ & $166 \pm 295$ & $0.7 \pm 0.9$ & $0.7 \pm 0.9$ & $0.5 \pm 0.4$ \\
\hline \multirow[t]{3}{*}{ MPZipNeo } & 11 & $2-4$ & $0.3 \pm 0.7$ & 0 & 0 & $0.8 \pm 0.4$ \\
\hline & 3 & 14 & 0 & $0^{\S}$ & $0^{\S}$ & 0 \\
\hline & 3 & $26-30$ & 0 & 0 & $0.2 \pm 0.2$ & $0.3 \pm 0.2$ \\
\hline
\end{tabular}

* Mean \pm SD of G-CSF activity in day 7 conditioned media from cultures initiated with $1 \times 10^{6}$ cells $/ \mathrm{ml}$ in $20 \%$ FCS, $10 \%$ PWM-SCM, except in $\$$, where cultures were initiated with $1 \times 10^{5}$ cells $/ \mathrm{ml} .{ }^{\ddagger} n=3$. 
Table III. Cellularity in Hemopoietic Tissues of Reconstituted Mice

\begin{tabular}{|c|c|c|c|c|c|c|}
\hline \multirow[b]{2}{*}{ Virus } & \multirow{2}{*}{$\begin{array}{l}\text { Number } \\
\text { of mice }\end{array}$} & \multirow{2}{*}{$\begin{array}{c}\text { Weeks after } \\
\text { transplantation }\end{array}$} & \multicolumn{4}{|c|}{ Number of cells $\left(\times 10^{-6}\right)^{*}$} \\
\hline & & & Per femur & Spleen & Peritoneum & Peripheral blood \\
\hline \multirow[t]{3}{*}{ MPZen(G-CSF) } & 9 & $2-4$ & $20 \pm 5$ & $611 \pm 203$ & $2.6 \pm 2.0$ & $34 \pm 29$ \\
\hline & 9 & $5-14$ & $21 \pm 4$ & $807 \pm 164$ & $5.2 \pm 1.7$ & $35 \pm 27$ \\
\hline & 10 & $26-30$ & $22 \pm 9$ & $620 \pm 257$ & $13 \pm 10$ & $22 \pm 13$ \\
\hline \multirow[t]{3}{*}{ MPZipNeo } & 11 & $2-4$ & $22 \pm 5$ & $246 \pm 54$ & $2.4 \pm 1.0$ & $1.3 \pm 0.8$ \\
\hline & 8 & $12-14$ & $22 \pm 4$ & $226 \pm 51$ & $6.0 \pm 2.6$ & $5.7 \pm 0.7$ \\
\hline & 3 & $26-30$ & $21 \pm 4$ & $153 \pm 38$ & $7.0 \pm 1.3$ & $4.0 \pm 1.5$ \\
\hline
\end{tabular}

* Mean \pm SD. ${ }^{\ddagger}$ Peripheral blood counts/ml.

fold above controls. Other cell types remained relatively unchanged.

A similar pattern of changes in total marrow and spleen progenitor numbers was observed with time (Table IV). Compared with controls, G-CSF and PWM-SCM responsive progenitors in the G-CSF mice were not significantly different in the marrow, but were elevated $\sim 30$ - and 80 -fold, respectively, in the spleen. Additionally, megakaryocyte-CFC (meg-CFC) numbers were unchanged in the marrow and elevated approximately twofold in the spleen (data not shown) while multipotential progenitor (mix-CFC) numbers in the total marrow and spleen were elevated threefold at $4 \mathrm{wk}$ after transplantation and declined to control values after $6 \mathrm{mo}$.

Peripheral blood and peritoneal G-CSF-responsive progenitors were found in 50 and $25 \%$ of the G-CSF mice, respectively, and never in the control animals. Similarly, PWMSCM-responsive progenitors were found six times more frequently in the G-CSF mice over the $6 \mathrm{mo}$.
In line with the changes in erythroblast numbers in G-CSF mice, erythroid progenitor cells were slightly decreased in the bone marrow and slightly elevated in the spleen and peripheral blood (Table V), the total effect being an approximate twofold increase in BFU-E and CFU-E numbers when compared to controls. However, no change in hematocrit values was observed, consistent with the absence of detectable erythropoietin in the sera of all mice.

In the absence of added CSF, $\sim 10 \%$ of bone marrow and spleen, and $1 \%$ of peripheral blood G-CSF-responsive progenitors of the G-CSF mice were factor independent while cells from the control animals exhibited an absolute dependency on exogenous CSF for proliferation (Table IV).

Overall, chronic overexpression of G-CSF in vivo led to a calculated approximate twofold increase in total body progenitors (BFU-E, CFU-E, Mix-CFC, GM-CFC, G-CFC, and Meg-CFC) but the relative frequencies between the various progenitors remained unaltered.

Table IV. Total Progenitor Cells in Hemopoietic Tissues of Reconstituted Mice

\begin{tabular}{|c|c|c|c|c|c|c|c|}
\hline \multirow[b]{2}{*}{ Virus } & \multirow{2}{*}{$\begin{array}{l}\text { Number } \\
\text { of mice }\end{array}$} & \multirow{2}{*}{$\begin{array}{l}\text { Weeks after } \\
\text { transplantation }\end{array}$} & \multirow[b]{2}{*}{ Stimulus } & \multicolumn{4}{|c|}{ Calculated total number of CFC $\left(\times 10^{-3}\right)^{*}$} \\
\hline & & & & Per femur & Spleen & Peritoneum & Peripheral blood ${ }^{\ddagger}$ \\
\hline \multirow[t]{9}{*}{ MPZen(G-CSF) } & 9 & $2-4$ & - & $0.2 \pm 0.2$ & $4 \pm 4$ & $0.02 \pm 0.02$ & $0.002 \pm 0.006$ \\
\hline & & & PWM-SCM & $23 \pm 7$ & $490 \pm 194$ & $0.07 \pm 0.08$ & $1.3 \pm 1.3$ \\
\hline & & & rhG-CSF & $6 \pm 4$ & $90 \pm 66$ & $0.03 \pm 0.03$ & $0.2 \pm 0.2$ \\
\hline & 9 & $5-14$ & - & $1 \pm 2$ & $20 \pm 40$ & $0.01 \pm 0.02$ & 0 \\
\hline & & & PWM-SCM & $27 \pm 6$ & $500 \pm 412$ & $0.1 \pm 0.1$ & $0.7 \pm 0.7$ \\
\hline & & & rhG-CSF & $4 \pm 4$ & $160 \pm 170$ & $0.02 \pm 0.04$ & $0.3 \pm 0.3$ \\
\hline & 10 & $26-30$ & - & $0.2 \pm 0.4$ & $1 \pm 2$ & 0 & 0 \\
\hline & & & PWM-SCM & $33 \pm 15$ & $130 \pm 60$ & $0.01 \pm 0.02$ & $0.02 \pm 0.01$ \\
\hline & & & rhG-CSF & $5 \pm 5$ & $20 \pm 20$ & 0 & 0 \\
\hline \multirow[t]{9}{*}{ MPZipNeo } & 7 & $2-4$ & - & 0 & 0 & 0 & 0 \\
\hline & & & PWM-SCM & $27 \pm 10$ & $80 \pm 40$ & $0.004 \pm 0.01$ & $0.01 \pm 0.02$ \\
\hline & & & rhG-CSF & $5 \pm 3$ & $7 \pm 5$ & 0 & 0 \\
\hline & 8 & $5-14$ & - & 0 & 0 & 0 & 0 \\
\hline & & & PWM-SCM & $42 \pm 13$ & $3 \pm 3$ & $0.003 \pm 0.006$ & 0 \\
\hline & & & rhG-CSF ${ }^{\S}$ & $7 \pm 5$ & 0 & 0 & 0 \\
\hline & 3 & $26-30$ & - & 0 & 0 & 0 & 0 \\
\hline & & & PWM-SCM & $40 \pm 10$ & $2 \pm 1$ & 0 & 0 \\
\hline & & & rhG-CSF & $11 \pm 4$ & 0 & 0 & 0 \\
\hline
\end{tabular}

* Mean \pm SD. ${ }^{\ddagger}$ CFC in $1 \mathrm{ml}$ peripheral blood. ${ }^{\S} n=3$. 
Table V. Total Multipotential (Mix-CFC) and Erythroid Progenitor Cells (BFU-E, CFU-E) in Hemopoietic Tissues

\begin{tabular}{|c|c|c|c|c|c|c|c|}
\hline \multirow[b]{2}{*}{ Virus } & \multirow[b]{2}{*}{$\begin{array}{l}\text { Number } \\
\text { of mice }\end{array}$} & \multirow[b]{2}{*}{$\begin{array}{l}\text { Weeks after } \\
\text { transplantation }\end{array}$} & \multirow[b]{2}{*}{ Cell type } & \multicolumn{4}{|c|}{ Total number of cells $\left(\times 10^{-3}\right)^{*}$} \\
\hline & & & & Per femur & Spleen & Peritoneum & Peripheral blood ${ }^{\ddagger}$ \\
\hline \multirow[t]{9}{*}{ MPZen(G-CSF) } & 9 & $2-4$ & CFU-E & $5 \pm 1$ & $964 \pm 580$ & 0 & 0 \\
\hline & & & BFU-E & $1 \pm 1$ & $210 \pm 210$ & $0.002 \pm 0.003$ & $0.3 \pm 0.5$ \\
\hline & & & Mix-CFC & $0.4 \pm 0.3$ & $50 \pm 64$ & $0.002 \pm 0.003$ & $0.1 \pm 0.1$ \\
\hline & 9 & $5-14$ & CFU-E & $12 \pm 2$ & $1870 \pm 2100$ & 0 & 0 \\
\hline & & & BFU-E & $2 \pm 1$ & $210 \pm 180$ & $0.001 \pm 0.003$ & $0.3 \pm 0.3$ \\
\hline & & & Mix-CFC & $0.8 \pm 0.5$ & $44 \pm 31$ & 0 & $0.05 \pm 0.05$ \\
\hline & 3 & $26-30$ & CFU-E & $3 \pm 2$ & $730 \pm 306$ & 0 & 0 \\
\hline & & & BFU-E & $0.7 \pm 0.4$ & $150 \pm 60$ & 0 & $0.08 \pm 0.04$ \\
\hline & & & Mix-CFC & $0.2 \pm 0.1$ & $26 \pm 14$ & 0 & $0.01 \pm 0.01$ \\
\hline \multirow[t]{9}{*}{ MPZipNeo } & 7 & $2-4$ & CFU-E & $20 \pm 10$ & $380 \pm 390$ & 0 & 0 \\
\hline & & & BFU-E & $2 \pm 1$ & $40 \pm 36$ & $0.01 \pm 0.02$ & $0.003 \pm 0.006$ \\
\hline & & & Mix-CFC & $0.7 \pm 0.4$ & $7 \pm 4$ & 0 & $0.004 \pm 0.008$ \\
\hline & 6 & 12 & CFU-E & $80 \pm 10$ & $120 \pm 90$ & 0 & 0 \\
\hline & & & BFU-E & $9 \pm 1$ & $12 \pm 8$ & 0 & 0 \\
\hline & & & Mix-CFC & $3 \pm 0$ & $3 \pm 2$ & 0 & 0 \\
\hline & 3 & $26-30$ & CFU-E & $50 \pm 20$ & $27 \pm 12$ & 0 & 0 \\
\hline & & & BFU-E & $5 \pm 3$ & $2 \pm 1$ & 0 & $0.003 \pm 0.002$ \\
\hline & & & Mix-CFC & $2 \pm 1$ & $1 \pm 0.1$ & 0 & $0.004 \pm 0.003$ \\
\hline
\end{tabular}

* Mean \pm SD. ${ }^{\ddagger} \mathrm{CFC}$ in $1 \mathrm{ml}$ peripheral blood.

Transplantation of infected hemopoietic cells into secondary recipients. During an observation period of $3 \mathrm{mo}$, all normal and sublethally irradiated secondary recipients remained healthy, and only two of the mice so far examined contained detectable G-CSF levels in the sera ( $250 \mathrm{U}$ in a non-irradiated mouse injected intraperitoneally, and $27,000 \mathrm{U}$ in the other sublethally irradiated mouse injected IV). In contrast, 6 of 19

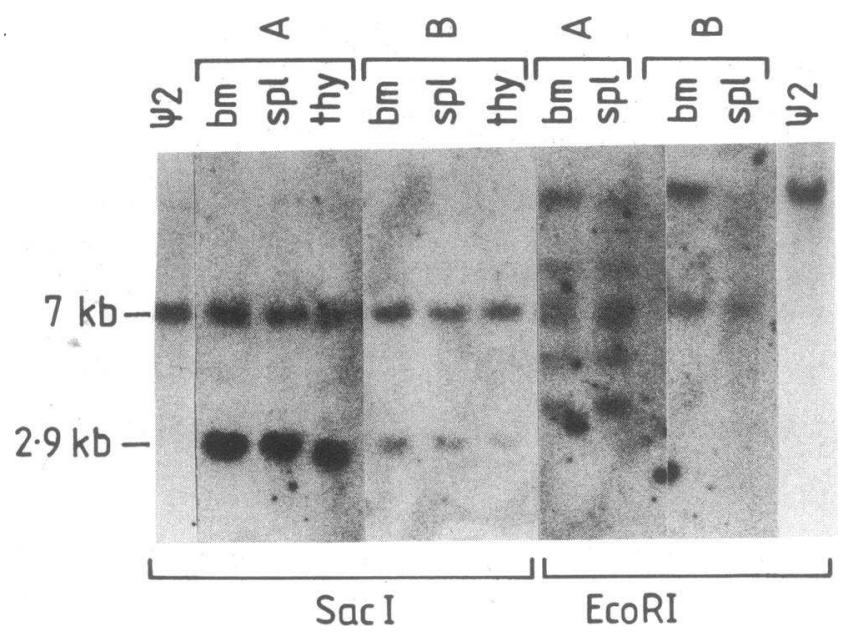

Figure 2. Detection of the MPZen(G-CSF) provirus in tissues from irradiated mice transplanted with virus-infected bone marrow cells. Southern blot analysis with a G-CSF cDNA probe of Sac I and Eco RI digested DNA from tissues (bm, bone marrow; spl, spleen; thy, thymus) of two mice ( $A$ and $B$ ) transplanted three months previously with $1 \times 10^{6} \mathrm{MPZen}(\mathrm{G}-\mathrm{CSF}$ )-infected post-5-FU-treated marrow cells, showing sizes of endogenous $(7.0 \mathrm{~kb})$ and proviral $(2.9 \mathrm{~kb})$ DNA digested with Sac I, which cuts within each LTR. lethally irradiated mice examined monthly between 22 and $106 \mathrm{~d}$ after transplantation continually showed consistently elevated G-CSF levels in the serum (mean 160,000, range $200-1,200,000 \mathrm{U} / \mathrm{ml}$ ), indicating the stable transmission of the inserted gene.

The absence of any synticium formation in the XC assay (34) induced by the G12 clone and the lack of transmissibility of G-CSF activity in the majority of nonirradiated secondary recipients suggest the absence of ecotropic replication-competent viruses in the primary animals.

Histological changes. The tissue changes exhibited by primary G-CSF mice were remarkably minor in comparison with those developing in mice with excess levels of GM-CSF (17) or Multi-CSF (18). Moreover, these changes that were present were more obvious at 5-8 wk after transplantation and declined thereafter with the exception of the excess hemopoiesis in the spleen.

The bone marrow exhibited an increased percentage of granulocytic cells but no other abnormality.

The spleen was enlarged due to increased cellularity in the red pulp. Lymphoid follicles were small in size and sometimes severely depleted of lymphoid cells. The most prominent cells in the red pulp were granulocytic at various stages of maturation (Fig. $4 A$ ) but in some spleens excess numbers of erythroid cells were also present. There was no accumulation of megakaryocytes and, in most spleens, eosinophil and mast cells were not prominent.

The liver displayed multiple, usually small, foci of neutrophilic granulocytes at varying differentiation stages (Fig. $4 \mathrm{~B}$ ). The foci in periportal areas sometimes also contained erythroid cells and, less commonly, eosinophils. No mast cells or megakaryocytes were present. There was no mitotic activity in liver cells and there were no areas of necrosis or cirrhosis. 


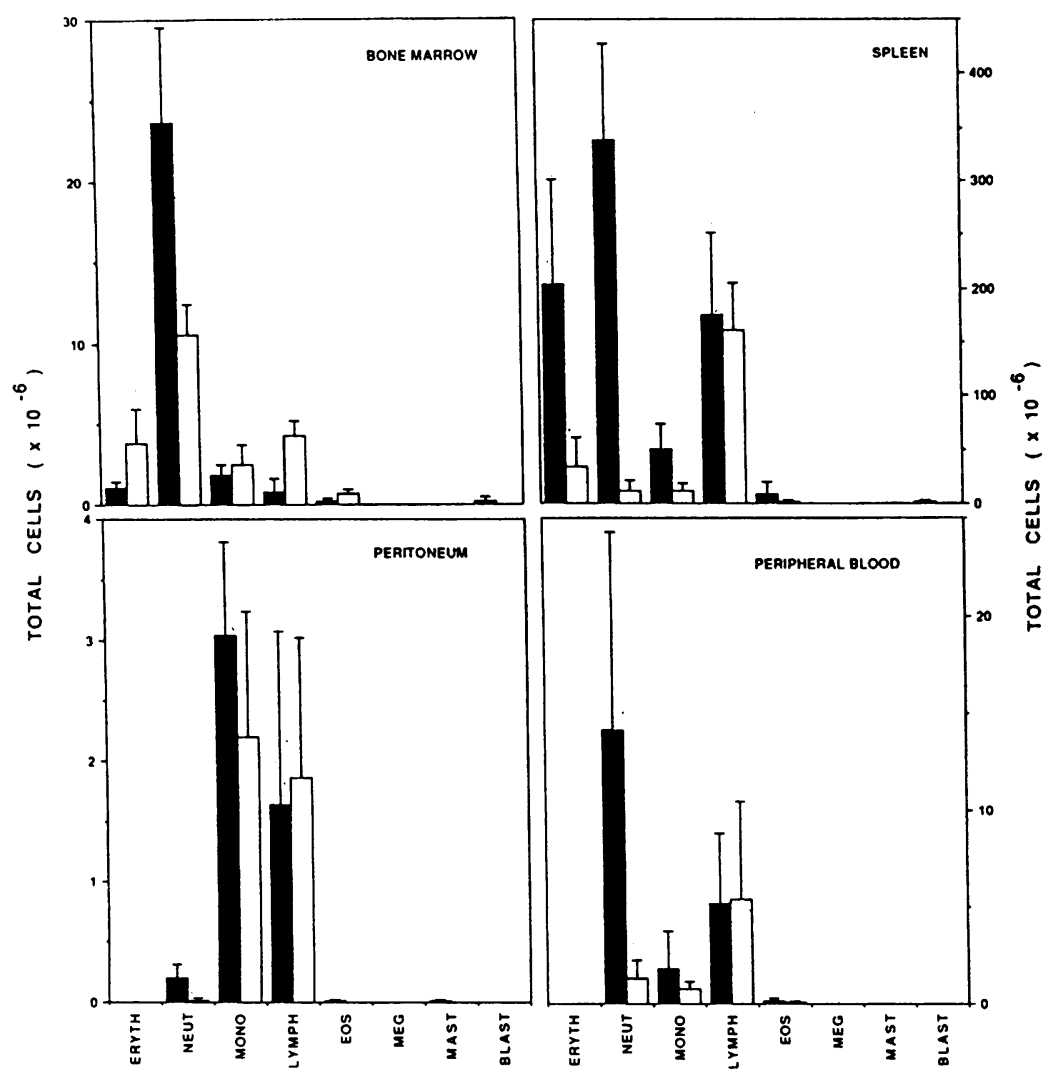

Figure 3. Total numbers of erythroblasts (eryth); myelocytes, metamyelocytes and polymorphs (neut); monocytes and macrophages (mono); lymphocytes (lymph), eosinophils (eos), megakaryocytes ( $m e g$ ), mast and blast cells in the bone marrow, spleen, peritoneal cavity, and peripheral blood of animals transplanted 3 mo previously with $10^{6}$ post-5-FU-treated bone marrow cells. Each column represents the mean and standard deviation of animals transplanted with mock-infected (open, $n=3$ ) or MPZen(G-CSF)-infected cells (closed, $n=6)$.
In most lungs the alveolar walls contained increased numbers of mature neutrophils (Fig. $4 E$ ). However, there were no peribronchial infiltrates, and no emphysema or pleural thickening.

No focal accumulations of hemopoietic cells were observed in striated muscle and the muscle cells exhibited no thinning. A striking exception was seen in some mice where the muscle tissue adjacent to the sternum contained infiltrating cords of mature neutrophils apparently extending from the adjacent sternal bone marrow (Fig. $4 C$ ). In such areas the muscle cells appeared undamaged (Fig. $4 \mathrm{D}$ ).

The heart showed no focal accumulations of hemopoietic cells and no evidence of pericarditis or endocarditis despite the presence of large numbers of mature granulocytes in the blood in the heart chambers.

No cellular infiltration or tissue damage was noted in the kidney, salivary gland, pancreas, gut, or skin. The mesenteric node occasionally contained small numbers of granulocytes in the hilar region. The thymus was normal in architecture with a wide lymphoid cortex indicating lack of stress in the animal.

\section{Discussion}

We have previously reported the effects of constitutive overproduction of GM-CSF (17) and multi-CSF (18) in vivo following transplantation of normal hemopoietic cells infected with MPZen type vectors containing cDNAs for these CSFs. These mice which expressed high levels of the relevant growth factor in their serum could not be studied over a long period of time since they developed a fatal but nonneoplastic myeloproliferative syndrome within several weeks after transplantation. The results described here provide further evidence that
MPZen vectors are able to infect stem cells capable of long term reconstitution of lethally irradiated mice, and that the infected cells continue to express the gene (G-CSF) over at least $6 \mathrm{mo}$. The stable transmission of the inserted gene is evident from the $30 \%$ efficiency at which lethally irradiated secondary hosts continue to express G-CSF for more than 3 mo. However, G-CSF serum levels in these animals varied considerably throughout the observation period and did not show any consistent pattern of expression even when the transplanted marrow cells were obtained from the same primary animal. This probably reflects subsequent activation of different stem cell clones at various times, as has been reported previously $(35,36)$.

Our experiments also imply that chronic stimulation of hemopoietic cells in vivo by G-CSF does not lead to a loss in marrow repopulating ability. Indeed, we (Chang et al., manuscript in preparation) and others $(9,37)$ have observed that this leads to an increase in marrow and spleen CFU-S numbers. The G-CSF mice also show an approximate twofold increase in progenitor numbers in the total marrow and spleen compared to controls. Interestingly, there was no increase in the proportion of G-CSF-responsive progenitors in the G-CSF mice, rather all progenitor types (BFU-E, CFU-E, GM-CFC, G-CFC, and Mix-CFC) increased proportionally relative to each other. Yet cytological and histological analysis revealed a selective increase of cells of the neutrophilic granulocytic series, a finding consistent with in vitro studies indicating the selective action of G-CSF on the differentiation and survival of this cell type (1-4). A similar pattern of response has been noted in patients injected with rhG-CSF (38).

It is noteworthy that the increase in progenitor and mature cells in the G-CSF mice was most evident soon after trans- 

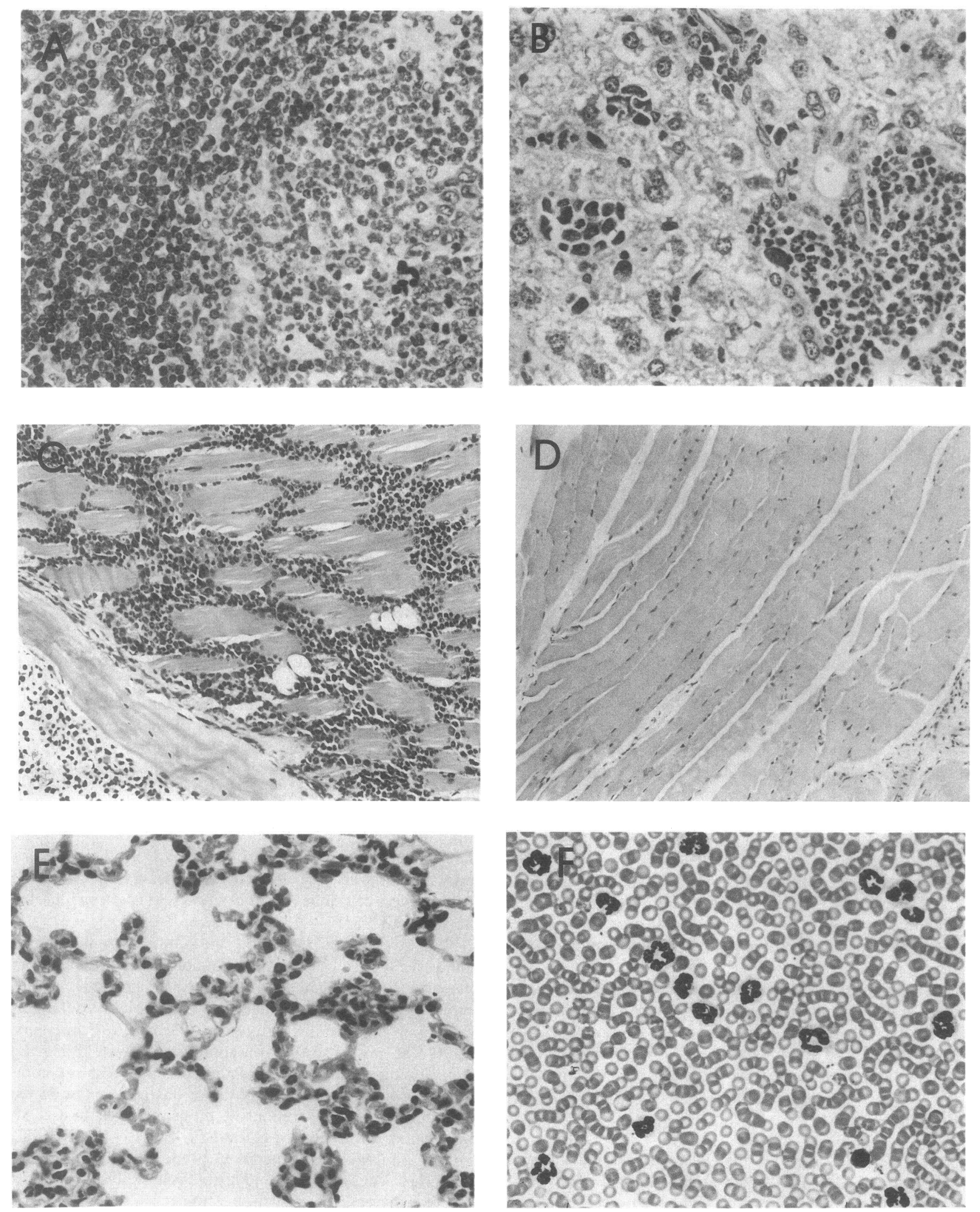

Figure 4. Photomicrographs of $(A)$ spleen showing infiltrating granulocytes in the red pulp, $(B)$ liver with foci of neutrophils at varying differentiation stages, $(C)$ sternal marrow with infiltrating cords of mature neutrophils into adjacent muscle, $(D)$ skeletal muscle with no foci of hemopoietic cells nor any signs of damage $(E)$ lung with increased numbers of mature neutrophils, and $(F)$ peripheral blood smear showing extensive neutrophilia. All photomicrographs of tissue from animals transplanted 5-8 wk previously with $10^{6}$ post-5-FU-treated marrow cells infected with MPZen(G-CSF). 
plantation, and declined with time. This may suggest a decline in gene expression with time, possibly due to the inactivation of the infected gene by various mechanisms such as methylation, as have been observed with $\mathrm{Neo}^{\mathrm{R}}$ gene expression which declined with time, and after secondary and tertiary transfers in mice (39). However, serum G-CSF levels remained consistently elevated, suggesting adequate expression of the viral gene at all times. The decline in cell numbers may therefore be due to an unusual hyporesponsiveness of hemopoietic cells to high G-CSF levels, perhaps due to a development of tolerance by responding cells from long-term repetitive stimulation. We are currently undertaking studies to test this hypothesis.

Previous studies using the MPZen vector expressing multiCSF (18) or the $\mathrm{Neo}^{\mathrm{R}}$ gene (28) have demonstrated that the regulatory elements within the viral LTR direct expression of the transduced gene in neutrophils, macrophages, B lymphocytes, T lymphocytes, erythroblasts, and mast cells. Since the LTR affects tissue-specific expression (40), presumably G-CSF is expressed in a similar range of hemopoietic cell types in the present studies. Further studies are currently underway to confirm this using fluorescence-activated cell sorting in conjunction with the polymerase chain reaction to detect expression of viral RNA in specific hemopoietic cell types at various times after transplantation.

The model system developed here provides a means to study the effects of chronic long-term exposure to a hemopoietic growth factor. Unlike the fatal disease and tissue damage occurring in mice with excess levels of GM-CSF (17) or multiCSF $(18,19)$, chronic elevations of G-CSF levels did not lead to premature death, and the mice exhibited remarkably little evidence of tissue damage. Indeed, apart from the excess hemopoiesis in the spleen, which caused organ enlargement, and the development of small hemopoietic foci in the liver, which were not progressive in nature, no histological evidence of tissue damage was observed in any organ. Specifically, the chronic presence of elevated numbers of mature granulocytes in lung alveolar walls did not apparently result in tissue damage.

It might have been anticipated that the substantial overproduction of mature granulocytes might lead to the development of the acute respiratory distress syndrome with associated damage to lung tissue (41). However such a sequence has not been observed in patients injected with G-CSF $(12,13)$ and was not observed in the present mice. The behavior of mice with chronically elevated G-CSF levels substantiates the increasing clinical experience that G-CSF elicits few toxic responses $(12,13)$ and that sustained elevations of granulocytes do not result in tissue damage, unlike the situation occurring when levels of macrophages are elevated $(17,42)$.

A curiosity noted in the G-CSF mice was the presence in some mice of infiltrating cords of mature granulocytes extending into adjacent intercostal muscle tissue from the sternal marrow. No comparable invasion was observed in muscle tissue adjacent to the femur. The phenomenon suggests the presence of unusual foramina in sternal bones permitting the selective egress of mature granulocytes from the marrow cavity under conditions of excess granulopoiesis in the adjacent marrow. Further toxicity studies can now be initiated to determine whether other more subtle changes have occurred in these animals (e.g., liver enzyme status) as no other model system presently provides continuous long-term exposure to G-CSF.

The absence of infiltrating granulocytes from organs such as the kidney and lymph nodes emphasizes the difference between this G-CSF-induced hyperplasia of granulocytic populations and myeloid leukemia in which such organs invariably show extensive infiltration. The non-neoplastic nature of the hyperplasia induced by chronic G-CSF stimulation was confirmed by failure of these cells to produce transplanted tumors in syngeneic recipients. The failure of mice with excess G-CSF levels to develop myeloid leukemia even after 6 mo confirms previous conclusions (17-19) that overstimulation of cell production is by itself insufficient to result in leukemic transformation.

\section{Acknowledgments}

The authors thank Jenny Beaumont and Elizabeth Viney for excellent technical assistance.

This work was supported by the National Health and Medical Research Council, Canberra, The Anti-Cancer Council of Victoria and The National Institutes of Health, Bethesda, MD, grant No. CA-25972.

\section{References}

1. Nicola, N. A., D. Metcalf, M. Matsumoto, and G. R. Johnson. 1983. Purification of a factor inducing differentiation in murine myelomonocytic leukemia cells. Identification as granulocyte colonystimulating factor. J. Biol. Chem. 258:9017-9023.

2. Metcalf, D., and N. A. Nicola. 1983. Proliferative effects of purified granulocyte colony-stimulating factor (G-CSF) on normal mouse hemopoietic cells. J. Cell. Physiol. 116:198-206.

3. Welte, K., E. Platzer, L. Lu, J. Gabrilove, E. Levi, R. Mertelsmann, and M. A. S. Moore. 1985. Purification and biochemical characterization of human pluripotent hematopoietic colony-stimulating factor. Proc. Natl. Acad. Sci. USA. 82:1526-1530.

4. Lopez, A. F., N. A. Nicola, A. W. Burgess, D. Metcalf, F. L. Battye, W. A. Sewell, and M. A. Vadas. 1983. Activation of granulocyte cytotoxic function by purified mouse colony-stimulating factors. J. Immunol. 131:2983-2988.

5. Tsuchiya, M., S. Asano, Y. Kaziro, and S. Nagata. 1986. Isolation and characterization of the cDNA for murine granulocyte colony-stimulating factor. Proc. Natl. Acad. Sci. USA. 83:7633-7637.

6. Nagata, S., M. Tsuchiya, S. Asano, Y. Kaziro, T. Yamazaki, O. Yamamoto, Y. Hirata, N. Kubota, M. Oheda, H. Nomura, and M. Ono. 1986. Molecular cloning and expression of cDNA for human granulocyte colony-forming factor. Nature (Lond.). 319:415-418.

7. Souza, L. M., T. C. Boone, J. Gabrilove, P. H. Lai, K. M. Zsebo, D. C. Murdock, J. Barendt, E. Platzer, M. A. S. Moore, R. Mertelsmann, and K. Welte. 1986. Recombinant human granulocyte colonystimulating factor: effects on normal and leukemic myeloid cells. Science (Wash. DC). 232:61-65.

8. Tamura, M., K. Hattori, H. Nomura, M. Oheda, N. Kubota, I. Imazeki, M. Ono, Y. Ueyama, S. Nagata, N. Shirafuji, and S. Asano. 1987. Induction of neutrophilic granulocytosis in mice by administration of purified human native granulocyte colony-stimulating factor (G-CSF). Biochem. Biophys. Res. Commun. 142:454-460.

9. Moore, M. A. S., K. Welte, J. Gabrilove, and L. M. Souza. 1987. Biological activities of recombinant human granulocyte colony stimulating factor (rhG-CSF) and tumor necrosis factor: in vivo and in vitro analysis. Haematology and Blood Transfusion. Vol. 31. Modern Trends in Human Leukemia. VII. Neth, Gallo, Greaves and Kabisch, editors. Springer-Verlag, Berlin, Heidelberg. 210-220.

10. Cohen, A. M., K. M. Zsebo, H. Inoue, D. Hines, T. C. Boone, V. R. Chazin, L. Tsai, T. Ritch, and L. M. Souza. 1987. In vivo stimulation of granulopoiesis by recombinant human granulocyte colony-stimulating factor. Proc. Natl. Acad. Sci. USA. 84:2484-2488.

11. Welte, K., A. M. Bonilla, A. P. Gillio, T. C. Boone, G. K. 
Potter, J. L. Gabrilove, M. A. S. Moore, R. J. O'Reilly, and L. M. Souza. 1987. Recombinant human granulocyte colony-stimulating factor. Effects on hematopoiesis in normal and cyclophosphamidetreated primates. J. Exp. Med. 165:941-948.

12. Bronchud, M. H., J. H. Scarffe, N. Thatcher, D. Crowther, L. M. Souza, N. K. Alton, N. G. Testa, and T. M. Dexter. 1987. Phase I/II study of recombinant human granulocyte colony-stimulating factor in patients receiving intensive chemotherapy for small cell lung cancer. Br. J. Cancer. 56:809-813.

13. Morstyn, G., L. Campbell, L. M. Souza, N. K. Alton, J. Keech, M. Green, W. Sheridan, D. Metcalf, and R. Fox. 1988. Effect of granulocyte colony stimulating factor on neutropenia induced by cytotoxic chemotherapy. Lancet. i:667-672.

14. Sporn, M. B., and A. B. Roberts. 1985. Autocrine growth factors and cancer. Nature (Lond.). 313:745-747.

15. Lang, R. A., D. Metcalf, N. M. Gough, A. R. Dunn, and T. J. Gonda. 1985. Expression of a hemopoietic growth factor cDNA in a factor-dependent cell line results in autonomous growth and tumorigenicity. Cell. 43:531-542.

16. Kawano, M., T. Hirano, T. Matsuda, T. Taga, Y. Horii, K. Iwato, H. Asaoku, B. Tang, D. Tanabe, H. Tanaka, A. Kuramoto, and T. Kishimoto. 1988. Autocrine generation and requirement of BSF-2/ IL-6 for human multiple myelomas. Nature (Lond.). 332:83-85.

17. Johnson, G. R., T. J. Gonda, D. Metcalf, I. K. Hariharan, and S. Cory. 1989. A lethal myeloproliferative syndrome in mice transplanted with bone marrow cells infected with a retrovirus expressing granulocyte-macrophage colony stimulating factor. EMBO (Eur. Mol. Biol. Organ.) J. 8:441-448.

18. Chang, J. M., D. Metcalf, R. A. Lang, T. J. Gonda, and G. R. Johnson. 1989. Non-neoplastic hemopoietic myeloproliferative syndrome induced by dysregulated Multi-CSF (IL-3) expression. Blood. 73:1487-1497.

19. Wong, P. M. C., S-W. Chung, C. E. Dunbar, D. M. Bodine, S. Ruscetti, and A. W. Nienhuis. 1989. Retrovirus-mediated transfer and expression of the interleukin-3 gene in mouse hematopoietic cells result in a myeloproliferative disorder. Mol. Cell. Biol. 9:798-808.

20. Cheng, G. Y. M., C. A. Kelleher, J. Miyauchi, C. Wang, G. Wong, S. C. Clark, E. A. McCulloch, and M. D. Minden. 1988. Structure and expression of genes of GM-CSF and G-CSF in blast cells from patients with acute myeloblastic leukemia. Blood. 71:204-208.

21. Marsh, J. L., M. Erfle, and E. J. Wykes. 1984. The pIC plasmid and phage vectors with versatile cloning sites for recombinant selection by insertional activation. Gene. 32:481-485.

22. Mann, R., R. C. Mulligan, and D. Baltimore. 1983. Construction of a retrovirus packaging mutant and its use to produce helper-free defective retrovirus. Cell. 33:153-159.

23. Southern, P. J., and P. Berg. 1982. Transformation of mammalian cells to antibiotic resistance with a bacterial gene under control of SV40 early region promoter. J. Mol. Appl. Gen. 1:327-341.

24. Dexter, T. M., J. Garland, D. Scott, E. Scolnick, and D. Metcalf. 1980. Growth of factor-dependent hemopoietic precursor cell lines. J. Exp. Med. 152:1036-1047.

25. Metcalf, D., and G. R. Johnson. 1978. Production by spleen and lymph nodes of conditioned medium with erythroid and other hemopoietic colony stimulating activity. J. Cell. Physiol. 96:31-42.

26. Bowtell, D. D. L. 1987. Rapid isolation of eukaryotic DNA. Anal. Biochem. 162:463-465.
27. Southern, E. M. 1975. Detection of specific sequences among DNA fragments separated by gel electrophoresis. J. Mol. Biol. 98:503-517.

28. Bowtell, D. D. L., G. R. Johnson, A. Kelso, and S. Cory. 1987. Expression of genes transferred to haemopoietic stem cells by recombinant retroviruses. Mol. Biol. Med. 4:229-250.

29. Metcalf, D. 1985. Molecular control of granulocyte and macrophage production. In Experimental Approaches for the Study of Hemoglobin Switching. G. Stamatoyannopoulos and A. Nienhuis, editors. Alan R. Liss, New York. 323-337.

30. Cutler, R. L., G. R. Johnson, and N. A. Nicola. 1985. Preparation of human erythropoietin for tissue culture. Exp. Hematol. 13:796-801.

31. Lala, P. K., and G. R. Johnson. 1978. Monoclonal origin of B-lymphocyte colony forming cells in spleen colonies formed by multipotential hemopoietic stem cells. J. Exp. Med. 148:1468-1477.

32. Chervenick, P. A., D. R. Boggs, J. C. Marsh, G. E. Cartwright, and M. M. Wintrobe. 1968. Quantitative studies of blood and bone marrow neutrophils in normal mice. Am. J. Physiol. 215:353-360.

33. Johnson, G. R., and D. Metcalf. 1977. Pure and mixed erythroid colony formation in vitro stimulated by spleen conditioned medium with no detectable erythropoietin. Proc. Natl. Acad. Sci. USA. 74:3879-3882.

34. Rowe, W. P., W. E. Pugh, and J. W. Hartlers. 1970. Plaque assay techniques for murine leukemia viruses. Virology. 42:11361139.

35. Lemischka, I. R., D. H. Raulet, and R. C. Mulligan. 1986. Developmental potential and dynamic behavior of hematopoietic stem cells. Cell. 45:917-927.

36. Snodgrass, R., and G. Keller. 1987. Clonal fluctuation within the haematopoietic system of mice reconstituted with retrovirus-infected stem cells. EMBO (Eur. Mol. Biol. Organ.) J. 6:3955-3960.

37. Moore, M. A. S., and D. J. Warren. 1987. Synergy of interleukin 1 and granulocyte colony-stimulating factor: In vivo stimulation of stem-cell recovery and hematopoietic regeneration following 5-fluorouracil treatment of mice. Proc. Natl. Acad. Sci. USA. 84:7134-7138.

38. Dührsen, U., J-L. Villeval, J. Boyd, G. Kannourakis, G. Morstyn, and D. Metcalf. 1988. Effects of recombinant human granulocytic-colony stimulating factor on hematopoietic progenitor cells in cancer patients. Blood. 72:2074-2081.

39. Keller, G., C. Paige, E. Gilboa, and E. F. Wagner. 1985. Expression of a foreign gene in myeloid and lymphoid cells derived from multipotent haematopoietic precursors. Nature (Lond.). 318:149-154.

40. Rosen, C. A., W. A. Haseltine, J. Lenz, R. Ruprecht, and M. W. Cloyd. 1985. Tissue selectivity of murine leukemia virus infection is determined by long terminal repeat sequences. J. Virol. 55:862-866.

41. Duchateau, J., and M. Lamy. 1988. Leukocyte aggregation and complement activation in respiratory distress syndrome (ARDS). Ann. Biol. Clin. (Paris). 46:267-268.

42. Lang, R. A., D. Metcalf, R. A. Cuthbertson, I. Lyons, E. Stanley, A. Kelso, G. Kannourakis, D. J. Williamson, G. K. Klintworth, T. J. Gonda, and A. R. Dunn. 1987. Transgenic mice expressing a hemopoietic growth factor gene (GM-CSF) develop accumulations of macrophages, blindness, and a fatal syndrome of tissue damage. Cell. 51:675-686. 